\title{
Discovery, development and SAR of aminothiazoles as LIMK inhibitors with cellular anti-invasive properties
}

\author{
Mark D. Charles ${ }^{1}$, Joanna L. Brookfield ${ }^{1}$, Tennyson C. Ekwuru ${ }^{1}, \dagger$ Martin Stockley $^{1}$, John Dunn ${ }^{1}$, \\ Michelle Riddick ${ }^{1}$, Tim Hammonds ${ }^{2}$, Elisabeth Trivier ${ }^{2}$, Gavin Greenland ${ }^{2}$, Ai Ching Wong ${ }^{2}$, Anne \\ Cheasty $^{1}$, Susan Boyd ${ }^{3}$, Diane Crighton ${ }^{4}$, Michael F. Olson ${ }^{4}$ \\ ${ }^{1}$ Cancer Research Technology Discovery Laboratories, Jonas Webb Building, Babraham Research Campus, Cambridge, CB22 \\ 3AT, UK; ${ }^{2}$ Cancer Research Technology Discovery Laboratories, London Bioscience Innovation Centre, Royal College Street, \\ London, NW1 0NH, UK; ${ }^{3}$ CompChem Solutions Ltd, St John's Innovation Centre, Cambridge, CB4 0WS; ${ }^{4}$ Cancer Research \\ UK, Beatson Institute, Garscube Estate, Switchback Road, Glasgow, G61 1BD
}

KEYWORDS: LIMK inhibitors, LIMK homology model, cancer cell invasion and metastasis, phospho-cofilin, inverse invasion assay

\begin{abstract}
As part of a program to develop a small molecule inhibitor of LIMK, a series of aminothiazole inhibitors were discovered by high throughput screening. Scaffold hopping and subsequent SAR directed development led to a series of low nanomolar inhibitors of LIMK1 and LIMK2 that also inhibited the direct biomarker p-cofilin in cells and inhibited the invasion of MDA MB231-luc cells in a matrigel inverse invasion assay.
\end{abstract}

Tumour cell invasion and metastasis are the primary causes of mortality in cancer patients. During progression of tumour cells to a metastatic phenotype, they undergo a series of changes that begin with loss of contact inhibition and increased motility, allowing them to migrate from the primary tumour site, invade distant organs and induce neovascularization resulting in metastasis. ${ }^{1}$ Despite numerous developments, cancer cell invasion and metastasis is still a poorly studied process. Most strategies to treat cancer do not rely on inhibiting invasion and metastasis as the primary phenotype due to the requirement for lengthy and complicated clinical trials. However a detailed understanding of the drivers of cancer cell invasion and migration is essential to develop new treatments for cancer patients.

The LIM kinases (LIMK1 and LIMK2; collectively LIMK) are TKL kinases that act downstream of Rho GTPases. LIM kinases phosphorylate and inactivate the filamentous-actin severing protein cofilin. Cycles of cofilin inactivation and activation enable dynamic actin rearrangements that are required for cell motility (Figure 1). Once phosphorylated at Ser3 by the LIM kinases cofilin can no longer bind to actin leading to the accumulation of actin polymers. LIM kinases are therefore centrally positioned regulators of actin cytoskeletal dynamics and also play important roles in microtubule organization., ${ }^{2,3}$

LIMK1 has been reported to play a key regulatory role in tumour cell invasion and the level of LIMK1 is increased in invasive breast, ${ }^{4}$ prostate, ${ }^{5}$ and pancreatic ${ }^{6}$ cancer cell lines in comparison with less invasive cells. Overexpression of LIMK1 in MCF-7 and in MDA MB-231 human breast cancer cell lines increased their motility, while inhibition of LIMK1 activity in MDA MB-231 cells by expression of a dominant negative LIMK1 resulted in decreased motility and formation of osteolytic bone lesions in an animal model of tumour invasion. ${ }^{7}$ As such, the LIM kinases have been proposed to be attractive drug targets to block tumour cell invasion and metastasis.

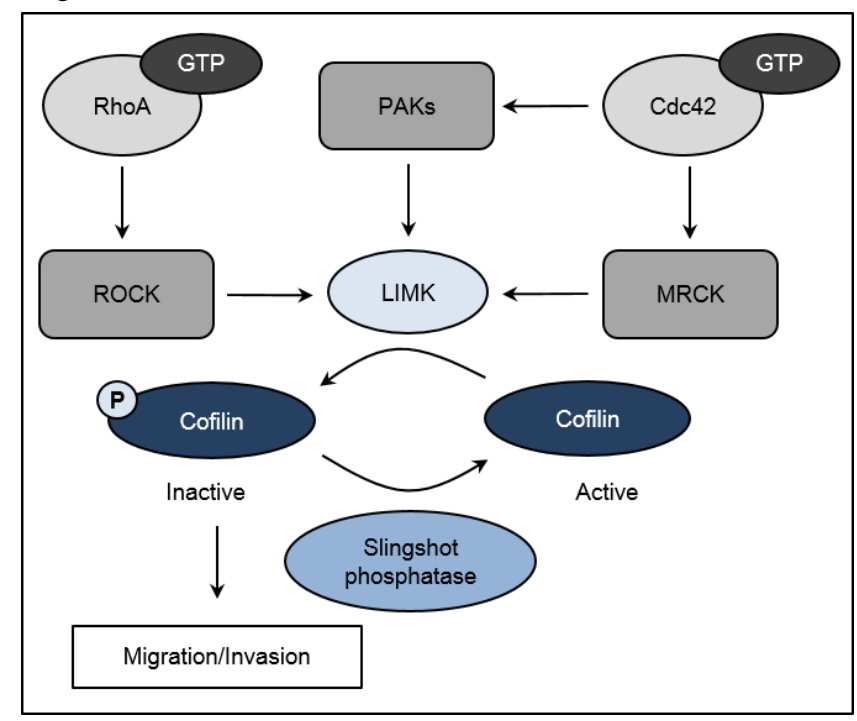

Figure 1 LIMK's are key regulators of the actin cytoskeleton, through their modulation of cofilin function.

A number of groups have previously reported inhibitors of the LIM kinases ${ }^{9-13}$ as treatments for cancer and for their ability to lower intraocular pressure for glaucoma. Herein we describe the discovery and development of a series of LIMK inhibitors that demonstrate inhibition of p-cofilin and inhibit invasion of cancer cells in a 3D inverse invasion assay.

We used a commercially available kinase Glo ${ }^{\circledR}$ kit measuring ATP depletion using full length LIMK and cofilin to screen 60,000 compounds. ${ }^{14}$ From this we identified two lead series, a series of pyrimidines that our partners CTx developed ${ }^{15,16}$ and a 
series of aminothiazoles exemplified by 1 LIMK $1 \mathrm{IC}_{50}=4 \mu \mathrm{M}$ (Figure 2) as modestly potent inhibitors of LIMK1. Although these compounds could be improved in terms of their isolated enzyme potency, no evidence of activity in the cellular assay was observed. They also contained numerous undesirable functionalities such as an alkene, a ketone and a potentially unstable methylene dioxy group. In removing the amino functionality, we reasoned that we could improve the cellular potency by reducing the $\mathrm{H}$ bond count. We also removed the undesirable ketone functionality, replacing it with a variety of groups. This led to pyridine $\mathbf{2}$ a compound that was similarly potent to the original hit 1. Bristol Myers Squibb reported that substituted pyrazoles with an aryl di-ortho chloro group were potent LIMK inhibitors. ${ }^{13}$ Similarly we found that pyridines substituted with aryl rings adjacent to the thiazole ring provided substantial improvements in potency as in 3a which had a LIMK1 potency of $15 \mathrm{nM}$. Even more importantly compound 3a was active in the p-cofilin cellular assay with an $\mathrm{IC}_{50}=3 \mu \mathrm{M}$.

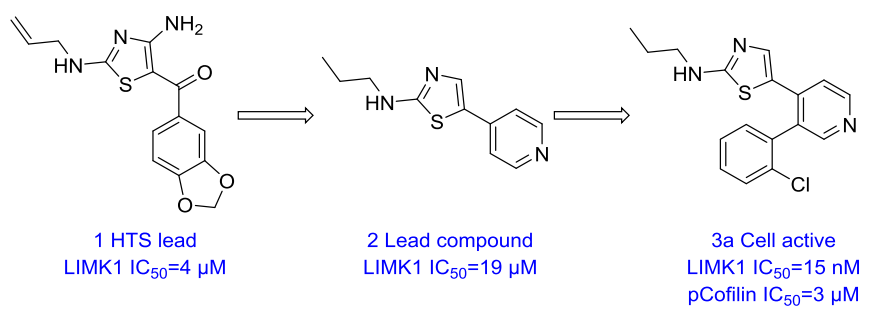

Figure 2 Evolution from original HTS lead

In order to better understand the binding mode, we created a homology model of the kinase domain of hLIMK1 based on cSrc (PDB code 1Y57.pdb) as a template. hLIMK shares $33.5 \%$ sequence identity and $50.6 \%$ sequence similarity with the c-Src template. Whilst there are some sequence inserts in the activation loop region (LIMK1 compared with c-Src) the rest of the sequences align well with no major inserts or deletions.

The improvements in potency were explained by docking 3a into the homology model (Figure 3). The amino thiadiazole in 1, 2 and 3a can form the key donor-acceptor interaction to the Ile428, Tyr 427 hinge residues. The pyridyl nitrogen present in $\mathbf{2}$ and 3a is well placed to interact with the salt bridge Lys 380 residue. This agreed well with the SAR because the other pyridine isomers $\mathbf{4 , 5}$ and $\mathbf{6}$ were much less potent than 3a (Figure 4). The chlorine atom was postulated to be making a halogen bond interaction to the Val 378 residue.

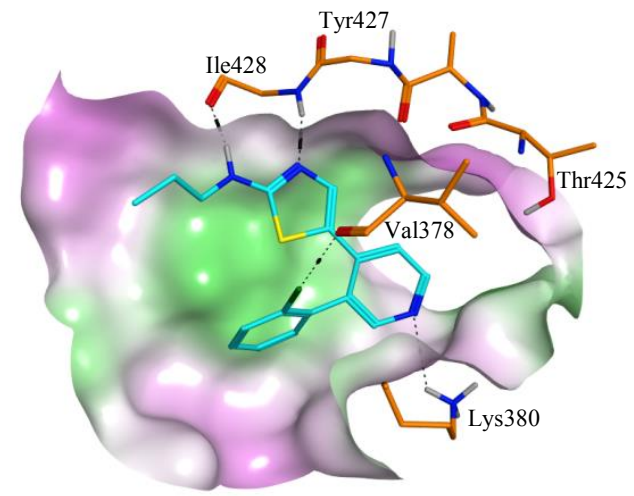

Figure 3 Compound 3a docked into a LIMK1 homology model based on c-Src (PDB code 1Y57.pdb) with surfaces coloured by lipophilicity, with purple indicating hydrophilic surfaces, green indicating lipophilic surfaces and neutral areas of the surface in white. Dotted lines indicate the key bonding interactions between the ligand and protein.

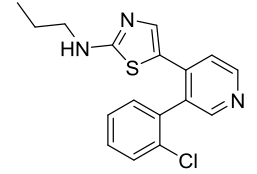

3a

LIMK1 IC ${ }_{50}=15 \mathrm{nM}$

LIMK1 IC $50=574 \mathrm{nM}$

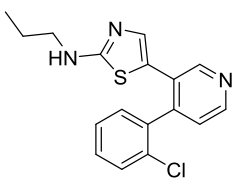

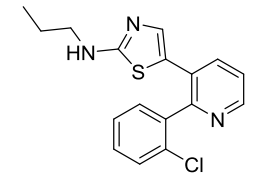

4

LIMK1 IC ${ }_{50}=327 \mathrm{nM}$

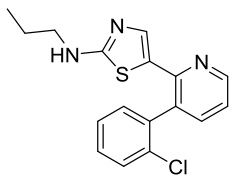

LIMK1 $\mathrm{IC}_{50}=>30000 \mathrm{nM}$
Figure 4 Pyridine isomer SAR

To understand the SAR and key binding interactions we set out to synthesize analogues of the cell active lead 3a. A variety of synthetic strategies were employed to allow late stage modifications of either the aryl ring (Scheme 1) or the amine side chain attached to the aminothiazole (Schemes 2 and 3).

Starting from the commercially available 3-bromopyridine-4carbaldehyde 7 and reducing to the alcohol $\mathbf{8}$ followed by chlorination with thionyl chloride to the benzyl chloride 9 proceeded smoothly. The thiazole ring could then be constructed by heating in acetonitrile with triethylamine and the appropriate amidines 10a-10c to provide the thiazoles 11 a-c. Protection of 11a with a Boc group allowed the introduction of a range of aryl groups via a Suzuki coupling to furnish after deprotection with TFA the final compounds 3a-3h. Compound 3i was prepared by an alternative route from $\mathbf{1 1 b}$ by di Boc protection to give $\mathbf{1 3}$ followed by Suzuki coupling to afford 14a,

Scheme 1 Synthetic access to aryl substituted pyridine analogues

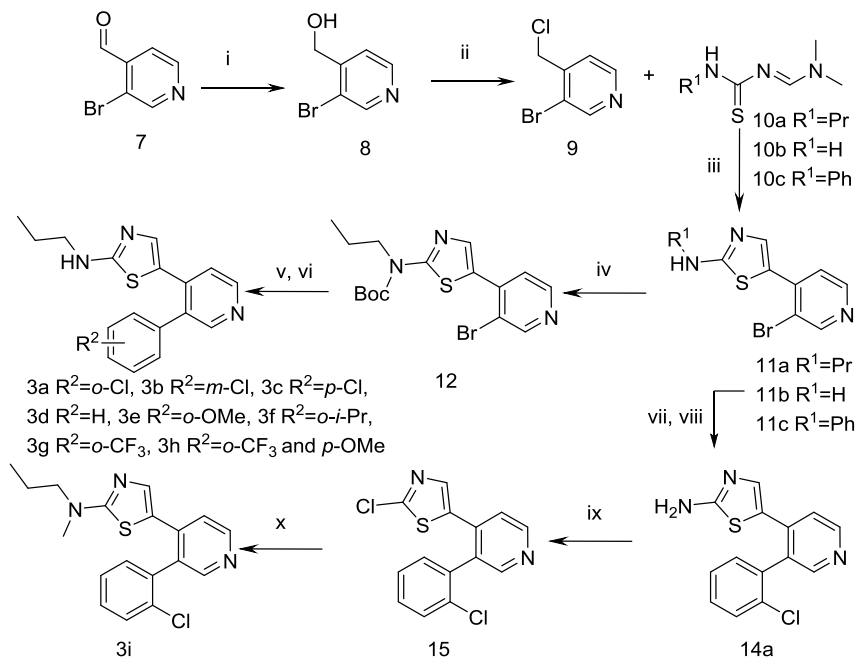

Reagents and conditions: (i) $\mathrm{NaBH}_{4}, \mathrm{MeOH}$, rt (ii) $\mathrm{SOCl}_{2}$, DCM, DMF, reflux (iii) $\mathrm{MeCN}, \mathbf{1 0 a}, 10 b$ or 10c, $\mathrm{Et}_{3} \mathrm{~N}$, reflux (iv) $\mathrm{Boc}_{2} \mathrm{O}$, DMAP, DCM, rt (v) $\left(\mathrm{PPh}_{3}\right)_{2} \mathrm{PdCl}_{2}, \mathrm{R}^{2} \mathrm{ArB}(\mathrm{OH})_{2}$, $\mathrm{K}_{2} \mathrm{CO}_{3}$, 1,4-dioxane, water, $150{ }^{\circ} \mathrm{C}$ (vi) TFA (vii) 3 equivs $\mathrm{Boc}_{2} \mathrm{O}$, DMAP, THF (viii) $\left(\mathrm{PPh}_{3}\right)_{2} \mathrm{PdCl}_{2}$, 2-chlorophenylboronic acid, $\mathrm{K}_{2} \mathrm{CO}_{3}$, 1,4-dioxane, water, $150{ }^{\circ} \mathrm{C}$ then TFA (ix) $\mathrm{NaNO}_{2}, \mathrm{HCl}(\mathrm{x}) \mathrm{NHMePr}, \mathrm{MeOH}, 150{ }^{\circ} \mathrm{C}$ 
Table 1 Initial aryl ring SAR investigations

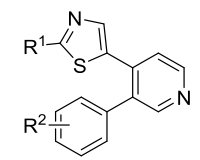

\begin{tabular}{|c|c|c|c|c|}
\hline Entry & $\mathrm{R}^{1}$ & $\mathrm{R}^{2}$ & $\begin{array}{c}\text { LIMK1 } \\
\mathrm{IC}_{50} \mu \mathrm{M}\end{array}$ & $\begin{array}{c}\text { Cell p-cofilin* } \\
\mathrm{IC}_{50} \mu \mathrm{M}\end{array}$ \\
\hline $3 \mathrm{a}$ & $-\mathrm{NHPr}$ & $0-\mathrm{Cl}$ & 0.015 & 3.8 \\
\hline $3 \mathrm{~b}$ & $-\mathrm{NHPr}$ & $m-\mathrm{Cl}$ & 0.50 & $\mathrm{ND}$ \\
\hline $3 \mathrm{c}$ & $-\mathrm{NHPr}$ & $p-\mathrm{Cl}$ & 0.62 & $\mathrm{ND}$ \\
\hline $3 \mathrm{~d}$ & $-\mathrm{NHPr}$ & $\mathrm{H}$ & 0.85 & $\mathrm{ND}$ \\
\hline $3 \mathrm{e}$ & $-\mathrm{NHPr}$ & $o-\mathrm{Me}$ & 0.082 & 11.5 \\
\hline $3 \mathrm{f}$ & $-\mathrm{NHPr}$ & $o-i-\mathrm{Pr}$ & 3.3 & $\mathrm{ND}$ \\
\hline $3 \mathrm{~g}$ & $-\mathrm{NHPr}$ & $o-\mathrm{CF}_{3}$ & 0.037 & 2.2 \\
\hline $3 \mathrm{~h}$ & $-\mathrm{NHPr}$ & $0-\mathrm{CF}_{3}$, & 0.013 & 2.5 \\
\hline $14 \mathrm{a}$ & $-\mathrm{NH} 2$ & $o-\mathrm{Cl}$ & 0.27 & $>30$ \\
\hline $3 \mathrm{i}$ & $-\mathrm{NMePr}$ & $o-\mathrm{Cl}$ & 3.1 & $\mathrm{ND}$ \\
\hline
\end{tabular}

*measured in ZR75-1 cells using a Cellomics array scan instrument. $\mathrm{ND}=$ not determined.

that could then be converted to the chloride $\mathbf{1 5}$ by diazotization in hydrochloric acid. Displacement with $\mathrm{N}$-propylmethylamine gave the final target $\mathbf{3 i}$.

Initial SAR modifications focused mainly on the aryl ring (Table 1) and demonstrated that the presence of an ortho substituent was required to provide activity, in particular where the group was ortho chloro as shown in entry 3a. The ortho chloro group could be replaced with methyl or trifluoro methyl although larger groups such as iso-propyl resulted in large losses in LIMK1 potency. Removal of the propyl side chain as in entry 14 or methylation of the $\mathrm{NH}$ as in entry $3 \mathbf{i}$ resulted in large losses in potency with the latter result being consistent with the proposed binding mode where the $\mathrm{NH}$ forms a key donor interaction to the hinge region of the kinase (Figure 3 ).

The amine side chain could be modified (Scheme 2) by di Boc protection of $\mathbf{1 1 b}$ to give $\mathbf{1 3}$ followed by a Suzuki coupling gave the Boc protected and the unprotected compounds $\mathbf{1 4 a}$ and $\mathbf{1 6}$ respectively. The mono Boc protected aminothiazole 14a could be derivatised using a Mitsunobu coupling providing a convenient method to deliver benzylamines $\mathbf{3 l}$ and $\mathbf{3 m}$. Alternatively 11b could be mono Boc protected to give 17, the amine side chain could be introduced via a Mitsunobu coupling to give 18a and $\mathbf{1 8 b}$. Suzuki couplings provided access to the targets $\mathbf{3 j}$ and 3k. Using an analogous strategy that was employed in (Scheme 1) $\mathrm{N}$-aryl analogues could be introduced by Boc protection of 11c to afford 19 and subsequent Suzuki coupling to yield 3n.
Scheme 2 Synthetic strategy to access amine side chain analogues

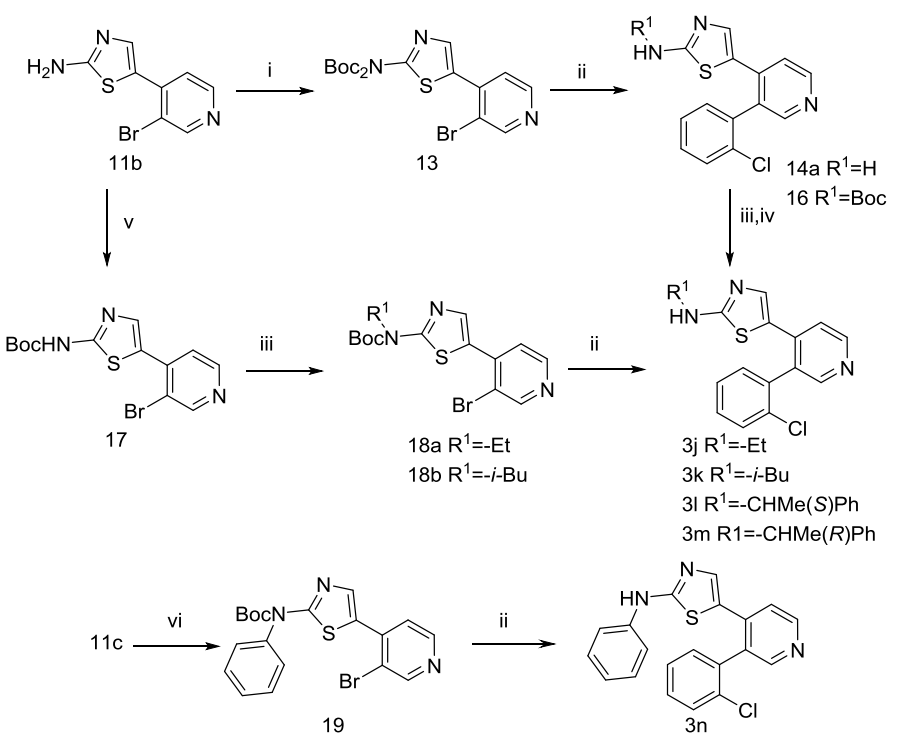

Reagents and conditions: (i) 3 equivs $\mathrm{Boc}_{2} \mathrm{O}$, DMAP, THF (ii) $\left(\mathrm{PPh}_{3}\right)_{2} \mathrm{PdCl}_{2}$, 2-chlorophenylboronic acid, $\mathrm{K}_{2} \mathrm{CO}_{3}$, 1,4-dioxane, water, $150{ }^{\circ} \mathrm{C}$ (iii) $\mathrm{R}^{1} \mathrm{OH}, \mathrm{DIAD}, \mathrm{PPh}_{3}$, THF (iv) TFA, DCM (v) $\mathrm{Boc}_{2} \mathrm{O}$, DMAP, DCM (vi) $\mathrm{Boc}_{2} \mathrm{O}$, DMAP, DCM

To allow further diversification of the aminothiazole side chain at the last step the aryl rings could be introduced on the alcohol intermediates 20a and 20b (Scheme 3), followed by chlorination to provide $21 \mathbf{a}$ and $\mathbf{2 1 b}$, thiazole formation with $\mathbf{1 0 b}$ or $\mathbf{1 0 d}$ provided final compound $3 \mathbf{o}$ and intermediates $\mathbf{1 4 b} \mathbf{b}$. . This then allowed for a series of amides to be prepared 22a-d.

The $N$-aryl analogue $\mathbf{3 n}$ in particular was very potent providing a compound that was sub micromolar in the p-cofilin cellular assay. Smaller alkyl groups such as ethyl $\mathbf{3 j}$ were less potent compared to iso-butyl $\mathbf{3 k}$ and benzylamines $\mathbf{3} \mathbf{l}$ and $\mathbf{3 m}$. Amides 22a-22d were also well tolerated particularly 22b which was $0.8 \mu \mathrm{M}$ in the $\mathrm{p}$-cofilin cellular assay.

Scheme 3 Synthetic strategy to access amide side chain analogues

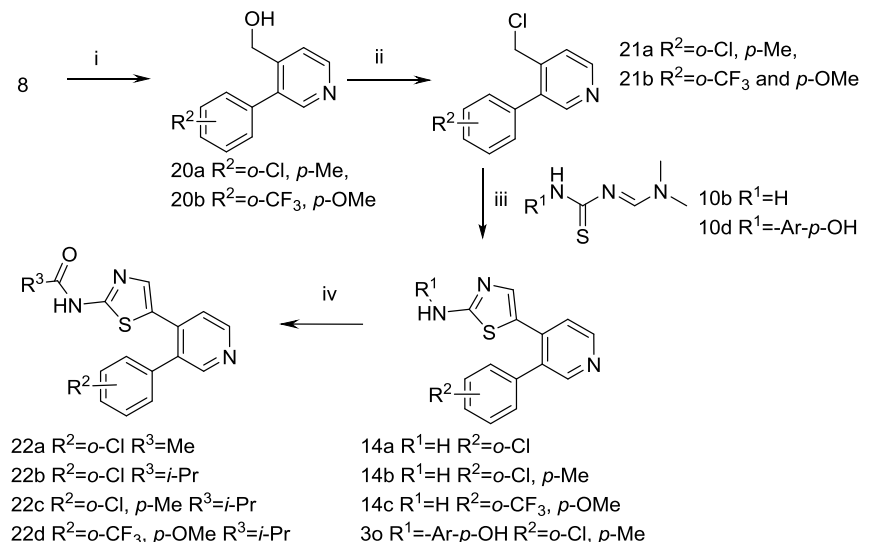

Reagents and conditions: (i) $\left(\mathrm{PPh}_{3}\right)_{2} \mathrm{PdCl}_{2}, \mathrm{R}^{2} \mathrm{ArB}(\mathrm{OH})_{2}$, $\mathrm{K}_{2} \mathrm{CO}_{3}$, 1,4-dioxane, water, $150{ }^{\circ} \mathrm{C}$ (ii) $\mathrm{SOCl}_{2}$, DCM, DMF, reflux (iii) $\mathrm{MeCN}, \mathbf{1 0 b}$ or $\mathbf{1 0 d}, \mathrm{Et}_{3} \mathrm{~N}$, reflux (iv) $\mathrm{R}^{3} \mathrm{COCl}, \mathrm{Et}_{3} \mathrm{~N}$, DCM, rt 
Table 2. SAR of amine side chain modifications

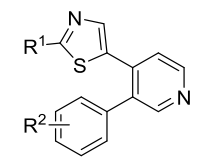

\begin{tabular}{|c|c|c|c|c|}
\hline Entry & $\mathrm{R}^{1}$ & $\mathrm{R}^{2}$ & $\begin{array}{c}\text { LIMK1 } \\
\mathrm{IC}_{50} \\
\mu \mathrm{M}\end{array}$ & $\begin{array}{c}\text { Cell p-co- } \\
\text { filin* } \text { IC }_{50} \\
\mu \mathrm{M}\end{array}$ \\
\hline $3 \mathrm{j}$ & -NHEt & $o-\mathrm{Cl}$ & 0.12 & 14 \\
\hline $3 \mathrm{k}$ & $-\mathrm{NH}-i-\mathrm{Bu}$ & $o-\mathrm{Cl}$ & 0.005 & 1.5 \\
\hline 31 & -NHCHMe $(S) \mathrm{Ph}$ & $o-\mathrm{Cl}$ & 0.04 & 9.2 \\
\hline $3 m$ & -NHCHMe $(R) \mathrm{Ph}$ & $o-\mathrm{Cl}$ & 0.004 & 2.1 \\
\hline $3 n$ & -NHPh & $o-\mathrm{Cl}$ & 0.003 & 0.6 \\
\hline 30 & -NH-4-PhOH & $\begin{array}{c}o-\mathrm{Cl}, p- \\
\mathrm{Me}\end{array}$ & 0.0003 & 6.6 \\
\hline $22 \mathrm{a}$ & -NHCOMe & $o-\mathrm{Cl}$ & 0.02 & 1.4 \\
\hline $22 b$ & -NHCO- $i$-Pr & $o-\mathrm{Cl}$ & 0.003 & 0.8 \\
\hline $22 \mathrm{c}$ & -NHCO- $i$-Pr & $\begin{array}{c}o-\mathrm{Cl}, p- \\
\mathrm{Me}\end{array}$ & 0.001 & ND \\
\hline $22 d$ & -NHCO- $i-\mathrm{Pr}$ & $\begin{array}{c}o-\mathrm{CF}_{3}, \\
p-\mathrm{OMe}\end{array}$ & 0.008 & 2.0 \\
\hline
\end{tabular}

*measured in ZR75-1 cells using a Cellomics array scan instrument. $\mathrm{ND}=$ not determined.

The ADME properties of the compounds required optimisation, in particular the alkyl substituted analogues were liable to high metabolic turnover in vitro. However the propyl group could be replaced with $N$-aryl analogues and amide groups. The amide analogue 22d in particular had lower in vitro microsomal turnover (Table 3).

Table 3. ADME properties and isoform selectivity of selected analogues

\begin{tabular}{|c|c|c|c|}
\hline Entry & 22c & 22d & 3o \\
\hline LIMK1 IC $50 / n M$ & 1 & 8 & 0.3 \\
\hline LIMK2 IC50/nM & 3 & 48 & 1 \\
\hline cLogP & 4.2 & 4.3 & 4.8 \\
\hline $\begin{array}{c}\text { Microsomes (m/h) } \\
\text { mL/min/g liver }\end{array}$ & $19.4 / 8.3$ & $5.2 / 3.7$ & $4.5 / 0.9$ \\
\hline PPB (h)/\% & 100 & 100 & 100 \\
\hline
\end{tabular}

In order to understand the functional effects of the compounds, we employed a 3D inverse invasion assay ${ }^{17}$ to measure the inhibition of invasion of cells into a matrigel matrix. In order to purely understand the metastatic phenotype it was necessary to select non-toxic compounds, so cell viability at $10 \mu \mathrm{M}$ was measured. We used an MTT cytotoxicity assay to select four compounds for further investigation based on their lack of cytotoxic effects (Table 4). To measure the invasive phenotype, MDA MB-231-luc cells were plated on the underside of a transwell filter plate. The ability of cells to invade was measured by confocal microscopy of sections through a matrigel plug. The percentage inhibition of invasion was measured as a function of the proportion of cells that invaded more than 60 $\mu \mathrm{m}$ into the matrigel plug compared to cells that invaded less than $60 \mu \mathrm{m}$, relative to the control. Compounds 3k, 22c, 22d and 3o all inhibited the invasion of the cells through matrigel at a concentration of $3 \mu \mathrm{M}$, whilst not significantly affecting cell viability even at the higher compound concentration of $10 \mu \mathrm{M}$. Compound 3o was found to be the most effective at inhibiting invasion. However the more selective compound 22d also significantly inhibited the invasion of the cells by $52 \%$. In addition, two other compounds $\mathbf{3 k}$ and $\mathbf{2 2} \mathbf{c}$ also inhibited invasion without having a marked effect on cell viability.

Table 4. Functional effects of selected LIMK inhibitors in an inverse invasion assay

\begin{tabular}{|c|c|c|}
\hline Entry & $\begin{array}{c}\text { MTT \% viable } \\
\text { cells @ } 10 \mu \mathrm{M} \\
\text { inhibitor }\end{array}$ & $\begin{array}{c}\text { \% inhibition of in- } \\
\text { vasion@ } 3 \mu \mathrm{M} \text { in } \\
\text { MDA MB-231-luc }\end{array}$ \\
\hline $3 \mathrm{k}$ & $88 \%$ & $34(\mathrm{n}=5)$ \\
\hline $22 \mathrm{c}$ & $131 \%$ & $48(\mathrm{n}=2)$ \\
\hline $22 \mathrm{~d}$ & $106 \%$ & $52(\mathrm{n}=3)$ \\
\hline $3 \mathrm{o}$ & $70 \%$ & $96(\mathrm{n}=3)$ \\
\hline
\end{tabular}

To measure selectivity against the LIMK2 isoform we developed an assay using a lanthabind format. The compounds were similarly potent Vs LIMK2 as LIMK1 (Table 3). The lead compounds were also profiled for their selectivity against a broader panel of 442 kinases using KINOMEscan ${ }^{\circledR}$ at Millipore (now DisoveRx). The selectivity of $\mathbf{2 2 d}, \mathbf{3 o}$ and $\mathbf{2 2 c}$ is represented in the kinome phylogenetic trees from screening at $10 \mu \mathrm{M}$ inhibitor concentration (Figure 5). Selectivity scores were calculated as the number of non mutant kinases with $\%$ activity relative to control $<35 /$ number of non mutant kinases tested. Compounds 22d and 22c were the particularly selective with selectivity $\mathrm{S}(35)$ scores of 0.083 and 0.132 respectively.
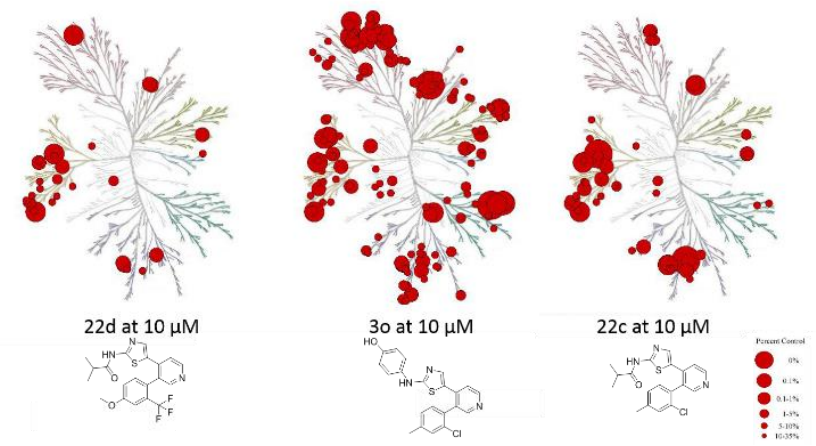

Figure 5 Kinase selectivity Vs 442 kinases for compounds 22d, 30 and 22c

In summary we have developed a series of novel LIMK inhibitors that are effective in inhibiting cellular invasion through a $3 \mathrm{D}$ matrix. An additional publication by Olson et al. ${ }^{18}$ will detail further biological data using compounds 22d and 3o (also known as CRT0105446 and CRT0105950 respectively) to investigate the effects of LIMK inhibition on microtubule organisation. The lead compounds are available externally for further profiling and investigation to determine their pharmacological applicability in conditions where LIMK plays a role.

\section{ASSOCIATED CONTENT}

Supporting Information. Detailed synthetic methods, analytical data, detailed selectivity data, procedures for the enzymatic and cellular assays and information on the computational approaches used can be found in the supplementary information. This material is available free of charge via the Internet at http://pubs.acs.org. 


\section{AUTHOR INFORMATION}

\section{Corresponding Author}

* Email: mcharles@cancertechnology.com

\section{Present Addresses}

$\dagger$ Mission Therapeutics, Babraham Research Campus, Cambridge CB22 3AT, UK

\section{ABBREVIATIONS}

TFA: Trifluoroacetic acid, DCM: Dichloromethane, DMF: $N, \mathrm{~N}$ Dimethyl formamide, DMAP: 4- $N, N$-Dimethyl amino pyridine, THF: Tetrahydrofuran, DIAD: Di-iso-propyl azodicarboxylate: MeCN: Acetonitrile, Boc: tert-Butyloxy carbonyl, PPB: Plasma protein binding, MTT: 3-(4,5-dimethylthiazol-2-yl)-2,5-diphenyltetrazolium bromide, RPMI: Roswell park memorial institute: FCS: Fetal calf serum, EGF: Epithelial growth factor, TKL: Tyrosine kinase like, GTP: Guanosine-5'-triphosphate, ATP: Adenosine triphosphate; HTS: High throughput screen; SAR: Structure activity relationship; PDB: Protein data bank; MOE: Molecular operating environment; ND: Not determined; m: mouse; h: human.

\section{REFERENCES}

(1) Nguyen, D. X.; Bos, P. D.; Joan Massagué. Metastasis: from dissemination to organ-specific colonization. Nature Rev. 2009, 9, 274284.

(2) Scott, R. W.; Hooper, S.; Crighton, D.; Li, A.; Konig, I.; Munro, J.; Trivier, E.; Wickman, G.; Morin, P.; Croft, D. R.; Dawson, J.; Machesky, L.; Anderson, K. I.; Sahai, E. A.; Olson, M. F. LIM kinases are required for invasive path generation by tumor and tumorassociated stromal cells. J. Cell. Biol. 2010, 191, 169-185.

(3) Scott, R. W.; Olson, M. F. LIM kinases: function, regulation and association with human disease. J. Mol. Med. (Berl). 2007, 85, 555568

(4) Bagheri-Yarmand, R.; Mazumdar, A.; Sahin, A. A.; Kumar, R. LIM kinase 1 increases tumor metastasis of human breast cancer cells via regulation of the urokinase-type plasminogen activator system. Int. J. Cancer 2006, 118, 2703-2710.

(5) Davila, M.; Frost, A. R.; Grizzle, W. E.; Chakrabarti, R. LIM Kinase 1 Is Essential for the Invasive Growth of Prostate Epithelial Cells. J. Biol. Chem. 2003, 278, 38, 36868-36875.

(6) Vlecken, D. H.; Bagowski, C. P. LIMK1 and LIMK2 are important for metastatic behavior and tumor cell-induced angiogenesis of pancreatic cancer cells. Zebrafish 2009, 6, 433-439.

(7) Yoshioka, K.; Foletta, V.; Bernard, O.; Itoh, K. A role for LIM kinase in cancer invasion. Proc. Natl. Acad. Sci. USA. 2003, 100, 72477252 .

(8) Harrison, B. A.; Whitlock, A. N.; Voronkov, M. V.; Almstead, Z. Y.; Gu, K-J.; Mabon, R.; Gardyan, M.; Hamman, B. D.; Allen, J.; Gopinathan, S.; McKnight, B.; Crist, M.; Zhang, Y.; Liu, Y.; Courtney,
L. F.; Key, B.; Zhou, J.; Patel, N.; Yates, P. W.; Liu, Q.; Wilson, A. G. E.; Kimball, D. S.; Crosson, C. E.; Rice, D. S.; Rawlins, D. B. Novel Class of LIM-Kinase 2 Inhibitors for the Treatment of Ocular Hypertension and Associated Glaucoma. J. Med. Chem. 2009, 52, 6515-6518.

(9) Prudent, R.; Vassal-Stermann, E.; Nguyen, C.; Pillet, C.; Martinez, A.; Prunier, C.; Barette, C.; Soleilhac, E.; Filhol, O.; Beghin, A.; Valdameri, G.; Honoré, S.; Aci-Sèche, S.; Grierson, D.; Antonipillai, J.; Li, R.; Di Pietro, A.; Dumontet, C.; Braguer, D.; Florent, J. C.; Knapp, K.; Bernard, O.; Lafanechère, L. Pharmacological Inhibition of LIM Kinase Stabilizes Microtubules and Inhibits Neoplastic Growth. Cancer Research 2012, 72, 4429-4439.

(10) He, L.; Seitz, S. P.; Trainor, G. L.; Tortolani, D.; Vaccaro, W.; Poss, M.; Tarby, C. M.; Tokarski, J. S.; Penhallow, B.; Hung, C. Y.; Attar, R.; An, Lin, T. A. Modulation of cofilin phosphorylation by inhibition of the Lim family kinases. Bioorg. Med. Chem. Lett. 2012, 22, 5995-5998.

(11) Yin, Y.; Zheng, K.; Eid, N.; Howard, S.; Jeong, J. H.; Yi, F.; Guo, J.; Park, C. M.; Bibian, M.; Wu, W.; Hernandez, P.; Park, H. J.; Wu, Y.; Luo, J-L.; LoGrasso, P. V.; Feng, Y. Bis-aryl urea derivatives as potent and selective LIM kinase (Limk) inhibitors. J. Med. Chem. 2015, 58, 1846-1861.

(12) Goodwin, N, C.; Cianchetta, G.; Burgoon, H. A.; Healy, J.; Mabon, R.; Strobel, E. B.; Allen, J.; Wang, S.; Hamman, B. D.; Rawlins D. B. Discovery of a Type III Inhibitor of LIM Kinase 2 That Binds in a DFG-Out Conformation. J. Med. Chem. Lett. 2015, 6 (1) 53-57. (13) Ross-Macdonald, P.; De Silva, H.; Guo, Q.; Xiao, H.; Hung, C. Y.; Penhallow, B.; Markwalder, J.; He, L.; Attar, R. M.; Lin, T-A.; Seitz, S.; Tilford, C.; Wardwell-Swanson, J.; Jackson, D. Identification of a nonkinase target mediating cytotoxicity of novel kinase inhibitors. Mol. Can. Ther. 2008, 7, 3490-3498.

(14) Mezna, M.; Wong, A. C.; Ainger, M.; Scott, R. W.; Hammonds, T.; and Olson, M. F; Development of a high-throughput screening method for LIM kinase 1 using a luciferase-based assay of ATP consumption. J. Biomol. Screen 2012, 17, 460-468.

(15) Sleebs, B. E.; Levit, A.; Street, I. P; Falk, H.; Hammonds, T.; Wong, A. C.; Charles, M. D.; Olson, M. F.; Baell, J. B. Identification of 3-aminothieno[2,3-b]pyridine-2-carboxamides and 4-aminobenzothieno[3,2-d]pyrimidines as LIMK1 inhibitors. Med. Chem. Comm. 2011, 10, 977-981.

(16) Sleebs, B.E., Nikolakopoulos, G., Street, I.P., Falk, H., and Baell, J.B. Identification of 5,6-substituted 4-aminothieno[2,3-d]pyrimidines as LIMK1 inhibitors. Bioorg. Med. Chem. Lett. 2011, 21, 5992-5994. (17) Hennigan, R. F.; Hawker, K. L.; Ozanne, B. W. Fos-transformation activates genes associated with invasion. Oncogene 1994, 9 , (12), 3591-3600.

(18) Mardilovich, K.; Baugh, M.; Crighton, D.; Kowalczyk, D.; Gabrielsen, M.; Munro, J.; Lourenco, F.; James, D.; Kalna, G.; McGarry, L.; Rath, O.; Shanks, E.; Garnett, M. J.; McDermott, U.; Brookfield, J.; Charles, M.; Hammonds, T.; Olson, M. F. LIM kinase inhibitors disrupt mitotic microtubule organization and impair tumor cell proliferation. Submitted. 